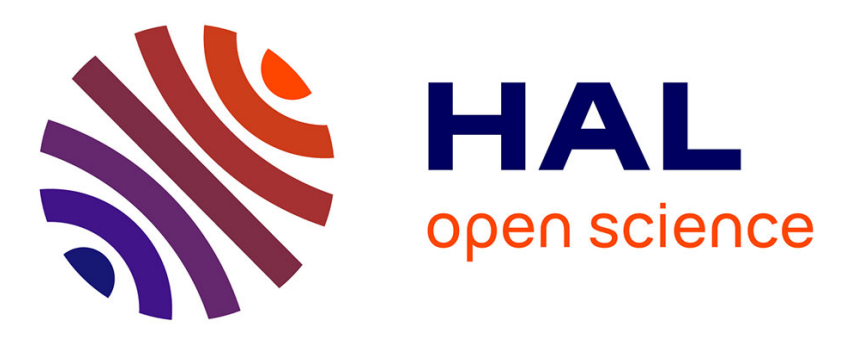

\title{
New members of the glutathione transferase family discovered in red and brown algae
}

Cécile Herve, Pierre-Olivier de Franco, Agnès Groisillier, Thierry Tonon, Catherine Boyen

\section{- To cite this version:}

Cécile Herve, Pierre-Olivier de Franco, Agnès Groisillier, Thierry Tonon, Catherine Boyen. New members of the glutathione transferase family discovered in red and brown algae. Biochemical Journal, 2008, 412 (3), pp.535-544. 10.1042/BJ20071464 . hal-00478902

\section{HAL Id: hal-00478902 https://hal.science/hal-00478902}

Submitted on 30 Apr 2010

HAL is a multi-disciplinary open access archive for the deposit and dissemination of scientific research documents, whether they are published or not. The documents may come from teaching and research institutions in France or abroad, or from public or private research centers.
L'archive ouverte pluridisciplinaire HAL, est destinée au dépôt et à la diffusion de documents scientifiques de niveau recherche, publiés ou non, émanant des établissements d'enseignement et de recherche français ou étrangers, des laboratoires publics ou privés. 
1 New members of the Glutathione transferase family discovered in Red

\section{2 and Brown algae}

3

4 Cécile HERVE $^{* \dagger}$, Pierre-Olivier de FRANCO ${ }^{* \dagger}$, Agnès GROISILLIER , Thierry

5 TONON $^{* \dagger}$ and Catherine BOYEN ${ }^{*+1}$

6

7 *UPMC Univ Paris 6, UMR 7139 Végétaux marins et Biomolécules, Station

8 Biologique, F 29682, Roscoff, France.

$9{ }^{\dagger}$ CNRS, UMR 7139 Végétaux marins et Biomolécules, Station Biologique, F 29682,

10 Roscoff, France

$11 \quad{ }^{1}$ To whom correspondence should be addressed (email boyen@sb-roscoff.fr).

13 Short title: Macroalgal GSTs

14

15 Abbreviations used: CDNB, 1-chloro-2,4-dinitrobenzene; EST, expressed sequence tag;

16 FDNB, 1-fluoro-2,4-dinitrobenzene; GSH, glutathione; GST, glutathione transferase; 4-

17 HNE, 4-hydroxynonenal; 12(+/-)-HpETE, 12-hydroperoxy-5Z,8Z,10E,14Z-

18 eicosatetraenoic acid; 13(S)-HpODE, 13S-hydroperoxy-9Z,11E-octadecadienoic acid;

19 13(S)-HpOTE, 13S-hydroperoxy-9Z,11E,15Z-octadecatrienoic acid; 15(S)-HETE, 15S-

20 hydroxy-5Z,8Z,11Z,13E-eicosatetraenoic acid; MAPEG, membrane-associated proteins

21 involved in eicosanoid and glutathione metabolism; MeJA, methyl jasmonate; PUFA,

22 polyunsaturated fatty acids. 
1 The GSTs (glutathione transferases) are involved in the detoxification of a wide variety

2 of hydrophobic substrates. These enzymes have been found in virtually all types of

3 organisms, including plants, animals, nematodes and bacteria. In the present study, we

4 report the molecular and biochemical characterization of algal GSTs. Phylogenetic

5 analysis showed that most of them were distinct from previously described GST classes

6 but were most closely related to the sigma class. Profiling of GST genes from the red

7 alga Chondrus crispus and brown alga Laminaria digitata was undertaken after

8 different chemical treatments and showed that they displayed contrasting patterns of

9 transcription. Recombinant algal GST from both species showed transferase activities

10 against the common substrates aryl halides, but also on the $\alpha, \beta$-unsaturated carbonyl 4-

11 hydroxynonenal. As well, they exhibit significant peroxidation towards organic

12 hydroperoxides, including oxygenated derivatives of polyunsaturated fatty acids.

13 Among a range of compounds tested, cibacron blue was the most efficient inhibitor of

14 algal GSTs identified.

15

16 Key words: Glutathione transferase, Chondrus crispus, Laminaria digitata,

17 phylogenetic classification, recombinant proteins, methyl jasmonate. 


\section{INTRODUCTION}

2

3 Among the cellular defense systems, GSTs (EC 2.5.1.18) form a highly diverse family

4 of proteins with functions ranging from detoxification to cell signaling. They are named

5 after their ability to catalyze the nucleophilic attack of GSH (glutathione) on

6 electrophilic substrates. In this manner, they contribute to the metabolism of drugs,

7 chemical carcinogens, pesticides and other xenobiotics [1]. Endogenous products

8 formed as secondary metabolites during oxidative stress are also substrates for GST

9 enzymes. In addition, several GSTs act as GSH-dependent peroxidases by catalyzing

10 the reduction of organic hydroperoxides to the less-toxic monohydroxy alcohols [2].

11 Beyond detoxification and involvement in various defense responses, there is increasing

12 evidence indicating that GSTs may be implicated in many other physiological processes

13 including isomerization of specific metabolites [3], transportation of endogenous

14 substrates [4], plant cell growth and development [5].

15 These proteins are found in almost all species and are divided into classes, based

16 primarily on sequence similarity. Currently recognized classes of cytosolic GSTs in

17 mammals include the Alpha, Mu, Omega, Pi, Sigma, Theta and Zeta classes [6]. GSTs

18 from the last two classes have also been identified in plants and other organisms. Other

19 distinct groups have been identified only in insects (Delta and Epsilon; [7]), plants

20 (Lambda, Phi, Tau; [1]), or prokaryotes (Beta; [8]). A Kappa class regroups

21 mitochondrial GSTs, and a family of microsomal GSTs comprises the membrane-

22 associated proteins designated MAPEG.

23 GST enzymes have been extensively purified from mammals, plants and 24 invertebrates [9]. In contrast, the occurrence of GSTs has not been explored in some 
1 taxa, such as the marine algae. Algae currently encompass eight groups of

2 photosynthetic eukaryotes which have evolved independently in the early history of life.

3 These organisms have acquired their plastids through different endosymbiotic events. A

4 first event involving a cyanobacterial ancestor gave rise to the red algae (Rhodophytae)

5 and the green plants (green algae and land plants). Brown algae (Phaeophyceae) and

6 diatoms stem from a secondary endosymbiotic event, and together with the oomycetes,

7 belong to the Heterokonts [10].

8 So far, there has been virtually no report on the molecular characterization of

9 GSTs in algae, particularly seaweed, mostly due to a lack of genomic information in

10 these organisms. Recently, we analyzed cDNA catalogs from thallus and protoplasts of

11 the red alga Chondrus crispus and of the brown alga Laminaria digitata, and provided

12 the first genetic evidence of cytosolic GST sequences in both organisms $[11,12]$. In the

13 present study, phylogenetic analyses demonstrate an unexpected link between

14 macroalgal GSTs and a large animal GST cluster including the Sigma class GSTs. We

15 thus propose that these red and brown algal GSTs, together with oomycetes

16 representatives, define a new group of GSTs closely-related to the Sigma class. In

17 addition expression profiling of these genes showed that red and brown algal GSTs

18 exhibit different patterns of transcription according to chemical treatments. Transferase

19 and peroxidase activities of the recombinant proteins from both algae were determined

20 in presence of different categories of substrates, and cibacronblue was determined as the

21 most effective inhibitor among the molecules tested. 


\section{EXPERIMENTAL}

2

\section{Plant material cultivation and chemical treatments}

5 Gametophytic Chondrus crispus unialgal isolates, and sporophytic Laminaria digitata

6 unialgal isolates, were cultivated at $13^{\circ} \mathrm{C}$ in enriched seawater medium SFC [13], using

7 a photoperiod of 10 hours of light and 14 hours of darkness and a photon flux density of $8 \quad 40 \mu \mathrm{mol} \mathrm{m} \mathrm{m}^{-2}$.

$\mathrm{CuSO}_{4}$ and $\mathrm{ZnCl}_{2}$ were purchased from Prolabo, and other chemicals from

10 Sigma. The derivatives of polyunsaturated fatty acids 13(S)-HpODE (13S-hydroperoxy-

11 9Z,11E-octadecadienoic acid), 13(S)-HpOTE (13S-hydroperoxy-9Z,11E,15Z-

12 octadecatrienoic acid), 12(+/-)-HpETE (12-hydroperoxy-5Z,8Z,10E,14Z-

13 eicosatetraenoic acid), 15(S)-HETE (15S-hydroxy-5Z,8Z,11Z,13E-eicosatetraenoic

14 acid), and 4-HNE (4-hydroxynonenal) were obtained from Cayman Chemicals.

15 Oligoguluronates were produced by enzyme degradation of sodium alginate [14].

16 To perform chemical treatments, algae were first maintained in Petri dishes with

17 seawater for at least 18 hours. Final concentrations of chemicals were as follows: 10

$18 \mathrm{mM} \mathrm{H}_{2} \mathrm{O}_{2} ; 500 \mu \mathrm{M}$ each tested pesticide; 100 or $200 \mu \mathrm{M}$ each heavy metal tested in $L$.

19 digitata and C. crispus respectively; $100 \mu \mathrm{M}$ MeJA (methyl jasmonate); 25 or $50 \mu \mathrm{M}$

20 each PUFA (polyunsaturated fatty acids) derivative in L. digitata and C. crispus

21 respectively; and $15 \mu \mathrm{g} \mathrm{mL}^{-1}$ oligoguluronates. An equal volume of solvent was used in each corresponding control treatment. After 3 and 6 hours of incubation for C. crispus

23 and L. digitata respectively, tissues were harvested, frozen in liquid nitrogen and stored 24 at $-80^{\circ} \mathrm{C}$ until use. 


\section{DNA and RNA isolation}

4 Extractions of genomic DNA and total RNA from gametophyte tissues of C. crispus

5 and sporophyte tissues of $L$. digitata were performed using the two-phase partitioning

6 protocol described in Hervé et al. [15]. To improve final yields with L. digitata tissues,

7 an additional step of polysaccharide precipitation, consisting of slow addition of $0.3 \mathrm{~V}$

8 of absolute ethanol to the extraction mixture, was included in the protocol before RNA

9 precipitation by $\mathrm{LiCl}$.

11 Identification of cDNA and corresponding genes encoding GST

13 EST encoding GSTs were identified in C. crispus and L. digitata through analysis of 14 corresponding cDNA libraries $[11,16]$. To obtain the genomic sequence of CCGST1, 15 CcGST2, CcGST3, LdGST1, LdGST2 and LdGST3 genes, PCR amplifications were 16 performed on genomic DNA using specific primers flanking the coding region of each 17 gene. The genomic sequence of LdGST4 could not be amplified in a single PCR, due to 18 the presence of large introns. All the primers used in this study are reported in

19 Supplementary Table S1. PCR conditions consisted of an initial denaturation of $5 \mathrm{~min}$ at $2095^{\circ} \mathrm{C}$, followed by 35 cycles of $45 \mathrm{~s}$ at $95^{\circ} \mathrm{C}, 60 \mathrm{~s}$ at $58^{\circ} \mathrm{C}$ and $100 \mathrm{~s}$ at $72^{\circ} \mathrm{C}$, and a final 21 extension of $10 \mathrm{~min}$ at $72^{\circ} \mathrm{C}$. PCR products were recovered from agarose gels, purified 22 using the Mini Elute Purification kit (Qiagen), and sequenced in both directions.

\section{Bioinformatic analysis}


2 Protein alignment was initially performed using the Mafft program at

$3 \mathrm{http}: / /$ bioinformatics.uams.edu/mafft/ and improved manually by comparison with a

4 structural alignment of GST proteins with resolved crystal structures from the Sigma, Pi

5 and Alpha classes. The alignment obtained was edited with ESPript at

6 http://espript.ibcp.fr/ESPript/ESPript/.

$7 \quad$ For phylogenetic analyses, full-length deduced amino acid sequences were

8 aligned using the Muscle 3.6 software [17]. For the most exhaustive analysis, 130

9 sequences were selected from public databases and used as representative members of

10 each of the known GST classes, excluding the microsomal MAPEG and mitochondrial

11 Kappa classes due to their extreme divergence. Oomycete (Phytophthora ramorum,

12 Phytophthora sojae) and algal sequences (Phaeodactylum tricornutum, Thalassiosira

13 pseudonana, Ostreococcus tauri, Ostreococcus lucimarinus, Cyanidioschyzon merolae

14 Chlamydomonas reinhardtii) were searched from genome projects or from public- and

15 restricted-access EST collections (Chondrus crispus, Gracilaria tenuistipitata,

16 Gracilaria gracilis, Gracilaria lemaneiformis, Porphyra yezoensis, Laminaria digitata,

17 Laminaria japonica Ectocarpus siliculosus, Fucus serratus, Fucus vesiculosus, Ulva

18 linza, Fragilariopsis cylindrus). The multiple-protein alignments were analyzed using

19 the neighbor-joining and maximum likelihood methods, based on distances derived

20 from the PAM matrix, with Mega 3.1 [18] and Phyml 2.4.4 [19] programs, respectively.

21 The robustness of the branches was evaluated using bootstrap replicates.

22 Sequences selected from public databases and used for the phylogenetic analysis

23 are listed in Supplementary Table S3.

24 
Real-time PCR

2

3 Total RNA were reverse transcribed using the Superscript II RT kit (Invitrogen), and

4 real-time PCR was performed in a GeneAmp 5700 sequence detection system using the

5 SYBR Green PCR master kit (Applied Biosystems) according to the manufacturer's

6 instructions. The primers used in the reaction were recommended by Primers Express

71.0 software (Applied Biosystems) and are listed in Supplementary Table S1. All 40

8 PCR cycles were performed according to the following temperature regimen: $95{ }^{\circ} \mathrm{C}$ for $9 \quad 15 \mathrm{~s}, 60{ }^{\circ} \mathrm{C}$ for $60 \mathrm{~s}$.

10 To generate a standard curve, genomic DNA of C. crispus and L. digitata were 11 used as reference matrixes. Knowing the genome mass of the C. crispus gametophyte 12 (0.16 pg) and the L. digitata sporophyte (1.4 pg), it was possible to determine the 13 number of cDNA molecules present in each sample tested as described in Hervé et al.

14 [15]. The quantity in unknown samples was expressed as a number of C. crispus or L.

15 digitata genomes per nanogram of total RNA. Actin and tubulin genes were used as 16 internal controls for $C$. crispus and $L$. digitata assays respectively, and corresponding 17 primers were designed based on sequences deposited in Genbank (accession numbers $18 \mathrm{U} 03676$ and AW400737, respectively).

19 The relative changes in the GST mRNA expression were calculated as $x$-fold 20 changes relative to the appropriate control experiment for the different chemical 21 treatments.

\section{Heterologous expression and protein purification}

24 
1 The open reading frames of the GST transcripts from C. crispus and L. digitata were

2 amplified by PCR using the primers listed in Supplementary Table S1. These primers

3 were designed to incorporate BamHI and EcoRI restriction sites into the 5' and ' 3 ' ends,

4 respectively. PCR conditions consisted of an initial denaturation of 5 min at $94^{\circ} \mathrm{C}$,

5 followed by 30 cycles of $30 \mathrm{~s}$ at $94^{\circ} \mathrm{C}, 30 \mathrm{~s}$ at $50^{\circ} \mathrm{C}$ and $2 \mathrm{~min}$ at $72^{\circ} \mathrm{C}$, and a final

6 extension step of $10 \mathrm{~min}$ at $72^{\circ} \mathrm{C}$. The resulting PCR products were purified, digested

7 with the appropriate restriction enzymes and subcloned into the pFO4 expression vector,

8 a vector modified from pET15 (Novagen) to be compatible with the BamHI/EcoRI and

$9 \mathrm{BamHI} / \mathrm{MfeI}$ ligation strategies.

10 Recombinant plasmids were used to transform Escherichia coli strain

11 BL21(DE3). Transformed colonies were grown at $37^{\circ} \mathrm{C}$ overnight in a Luria-Bertani

12 medium containing ampicillin. The culture was diluted 1:100 with auto-inducible ZYP

13 medium [20] containing ampicillin and subjected to further incubation at $20^{\circ} \mathrm{C}$ until the

14 culture density reached saturation. After centrifugation, pelleted bacteria were

15 resuspended in Tris- $\mathrm{HCl} \mathrm{pH} 7.5$ buffer containing $300 \mathrm{mM} \mathrm{NaCl}$ and $60 \mathrm{mM}$ imidazole

16 and disrupted using a French press prior to centrifugation. The resulting supernatant was

17 applied onto a Chelating Fast Flow Sepharose column charged with $100 \mathrm{mM} \mathrm{NiSO}_{4}$

18 (Amersham Biosciences). After washing, the bound proteins were eluted with a linear

19 gradient of imidazole ranging from $60 \mathrm{mM}$ to $300 \mathrm{mM}$. The protein eluted was collected

20 and dialyzed against a buffer containing $20 \mathrm{mM}$ Tris- $\mathrm{HCl} \mathrm{pH} 7.5,100 \mathrm{mM} \mathrm{NaCl}, 1 \mathrm{mM}$

21 EDTA and $1 \mathrm{mM}$ DTT. Glycerol was added to dialyzed proteins to a final concentration

22 of $20 \%(\mathrm{v} / \mathrm{v})$ before storage at $-80^{\circ} \mathrm{C}$. Final protein concentrations were estimated by

23 the Bradford method with reagents purchased from Bio-Rad. The apparent molecular

24 mass of the purified recombinant proteins was evaluated by size-exclusion 
1 chromatography using a $1.6 \mathrm{~cm} \times 60 \mathrm{~cm}$ Superdex 200 column (Amersham Pharmacia

2 Biotech). The column was equilibrated in $50 \mathrm{mM}$ Tris- $\mathrm{HCl} \mathrm{pH} 7.5$ buffer containing

$3100 \mathrm{mM} \mathrm{NaCl}$. Molecular masses of standards used for calibration are: carbonic

4 anhydrase, $29 \mathrm{kDa}$; serum albumine bovine, $66 \mathrm{kDa}$; alcohol dehydrogenase, $150 \mathrm{kDa}$;

$5 \quad \beta$-amylase, $200 \mathrm{kDa}$; apoferritin, $443 \mathrm{kDa}$; thyroglobulin, $669 \mathrm{kDa}$; blue dextran 2,000 $6 \mathrm{kDa}$.

7

$8 \quad$ Enzyme assays

10 GST enzyme activity assays were carried out in a microplate Safire ${ }^{2}$ UV 11 spectrophotometer reader (Tecan), except for 4-HNE and trans-2-nonenal that used a

12 UV-2401-PC spectrophotometer (Shimadzu). In all instances, the non-enzymatic

13 reaction was measured and subtracted from the overall reaction rate. Assays were 14 conducted at $30^{\circ} \mathrm{C}$ and measures were performed during 10 min after addition of second 15 substrate. Ethacrynic acid, trans-4-phenyl-3-buten-2-one, para-nitrophenyl acetate and 16 cumene hydroperoxide were generously provided by Fabrice Morel (U620 Inserm, 17 Rennes, France). Except the PUFA hydroperoxides and the 4-HNE obtained from 18 Cayman chemicals, all chemicals were purchased from Sigma.

19 Glutathione transferase and glutathione peroxidase activities were measured as 20 reported by Thomson et al. [21]. Enzyme activity with aldehydes 4-HNE and trans-221 nonenal was assessed as reported by Alin et al. [22]. Substrate concentrations for each 22 test are given in the Supplementary Table S2. A unit of enzyme activity is defined as the 23 amount of enzyme that catalyses the turnover of $1 \mu \mathrm{mol}$ substrate per min. Specific 24 activity is expressed in $\mu \mathrm{mol} \mathrm{min}^{-1}$ per mg of enzyme. The apparent $\mathrm{Km}$ value for GSH 
1 was determined using GSH concentration ranging from $250 \mu \mathrm{M}$ to $2 \mathrm{mM}$, and a fixed

2 CDNB concentration of $2 \mathrm{mM}$. Kinetic parameters were calculated by the method of

3 Lineweaver-Burk.

4 Inhibitory effects on enzyme activity were measured by pre-incubating the 5 enzymes $5 \mathrm{~min}$ in presence of GSH ( $1 \mathrm{mM}$ final concentration) and several quantities of 6 inhibitor (from $0.05 \mu \mathrm{M}$ to $2 \mathrm{mM}$ final concentration). Reactions were initiated by 7 addition of 1-chloro-2,4-dinitrobenzene (CDNB; final concentration of $1 \mathrm{mM}$ ). The 8 concentration of each inhibitor giving $50 \%$ inhibition $\left(\mathrm{IC}_{50}\right)$ was determined 9 graphically. 


\section{$1 \quad$ RESULTS}

2

\section{Sequence analysis of cDNA-encoding algal GSTs}

4

5 Seven putative cytosolic GSTs were identified through analysis of algal EST libraries:

6 three from the rhodophyte C. crispus (CcGST1, CcGST2, CcGST3) and four from the

7 phaeophyte L. digitata (LdGST1, LdGST2, LdGST3, LdGST4). Their length ranged

8 from 201 to 230 amino acids. In both protoplast libraries, these GST genes were among

9 the most represented sequences. The cDNA sequences corresponding to the complete

10 coding regions of these GSTs have been deposited in GenBank under the following 11 accession numbers: EF423557 for CcGST1, EF423558 for CcGST2, EF423559 for

12 CcGST3, EF422836 for LdGST1, EF424837 for LdGST2, EF422838 for LdGST3 and EF422839 for LdGST4.

The GenBank database was searched using the protein blast program and revealed that CcGST1, CcGST2, LdGST1, LdGST2, LdGST3 and LdGST4 were most similar to Sigma-class enzymes, with a maximum of $33 \%$ identity. Conserved residues usually encountered in GST classes from mammals were also found in the algal sequences. Of significance was the highly conserved catalytic tyrosine found in the early N-terminal portion of most mammalian GSTs (Figure 1; [21]). In the mammalian $\mathrm{Pi}, \mathrm{Mu}$ and Sigma classes, the glutamine and serine residues just prior to the $\alpha 3$-helixe are also involved in the interaction with GSH [9]. Compared to other Sigma-class GST members, the $\mathrm{C}$-terminal domain of the algal sequences were highly divergent, which may indicate different substrate selectivities and specificities of the algal GSTs. In contrast to the other GSTs identified in this study, CcGST3 shared higher identities (25- 
$126 \%$ with sequences from the Zeta, Beta, Delta and Epsilon classes. Two tyrosine

2 residues are found in the early N-terminal portion of the CcGST3 sequence and may be

3 involved in the GSH binding (see Supplementary Figure S1).

The similarity of amino acids between the six most-related algal sequences was

5 28-63\%, indicating a high degree of heterogeneity. The highest identities were

6 observed between CcGST1 and CcGST2 (51\%), and between LdGST1, LdGST2 and

7 LdGST3 (50-63\%). LdGST4 was the most divergent among the L. digitata sequences,

8 as CcGST3 was among the C. crispus sequences.

While classification in different GST families can be based on sequence

10 similarities alone, distinct gene structure provides additional supporting evidence [1,

11 23]. Therefore, the cDNA sequences of C. crispus and L. digitata GSTs were compared

12 with their corresponding genomic DNA sequences. The genes encoding CcGST3,

13 LdGST1, LdGST2 and LdGST3 were intronless. CcGST1 holds an intron of $93 \mathrm{bp}$,

14 whose size and position coincides exactly with those of the unique intron of $100 \mathrm{bp}$

15 encountered in CcGST2 (Figure 2). The LdGST4 genomic sequence contains four exons

16 and three introns. Their length could not be determined accurately due to the low PCR-

17 product yield for this gene. This could be attributed to the presence of large introns in

18 the sequence.

19

20 Phylogenetic position of algal GSTs

21

22 In order to elucidate phylogenetic relationships between the identified algal GSTs with

23 sequences from other organisms, we searched for additional GST genes using genomic

24 resources available for micro- and macroalgae. Among the sequences identified, 7 full- 
1 length putative cytosolic GST genes that are well supported by ESTs were considered

2 for further analyses. These sequences were as follow: two from Gracilaria tenuistipitata

3 (Rhodophyta), one from the green macroalga Ulva linza (Chlorophyta) and four for the

4 brown macroalga Ectocarpus siliculosus (Phaeophyceae). They will be made available

5 upon request to the authors. Sequences from the oomycetes Phytophthora sojae and

6 Phytophthora ramorum were also taken into account. Two other previously identified

7 GST sequences were also included: CspGST1 from the green unicellular alga

8 Coocomyxa sp. [24] and PiGST1 from the oomycete Phytophthora infestans [25]. The

9 red alga CcGST3 sequence was not included due to its highly divergent pattern. In total,

10155 sequences were integrated in a multiple protein alignment. Several optimal trees

11 were then generated from both distance and maximum likelihood methods, and their

12 topologies were essentially the same, with slight differences observed in the bootstrap

13 values supporting the nodes. The most reliable tree is presented in Figure 3. Two major

14 groups of GST proteins can be established, in agreement with previous studies [26, 27].

15 The first group contains proteins specific of different eukaryotic organisms, as plants

16 (Tau, Lambda and Phi classes), animals (Omega class) and insects (Delta and Epsilon

17 classes). The Zeta and Theta classes have counterparts in plants and animals, and

18 several sequences from the oomycetes $P$. sojae and $P$. ramorum can also be found close

19 to these classes. This phylogeny confirms that the recently described Rho class, thought

20 to be fish-specific, also comprises green algal sequences [24]. The second major group

21 includes the Alpha, $\mathrm{Pi}, \mathrm{Mu}$ and Sigma classes, primarily encountered in mammals. Most

22 of the newly isolated sequences from this study fall into this group and are closely

23 related to the Sigma GST members. Because of this unexpected distribution, we

24 undertook a more focused phylogenetic analysis, restricted to GSTs of the Alpha, Mu, 
$1 \mathrm{Pi}$ and Sigma classes and including the "algae-oomycetes" sequences (see

2 Supplementary Figure S2). The overall topology already observed in the previous

3 phylogenetic tree was confirmed and a more detailed analyze is discussed on line.

\section{Different transcription patterns for brown and red algal GSTs}

6

7 In both C. crispus and L. digitata, GST sequences were identified through analysis of

8 protoplast cDNA libraries and were among the most represented genes, suggesting a

9 possible role of these enzymes in detoxification processes during protoplast generation.

10 Changes in expression of these genes were further investigated under different chemical

11 treatments and after short exposure times (Figure 4).

12 In the red alga C. crispus, treatments with $\mathrm{H}_{2} \mathrm{O}_{2}$, the auxin analogue 2,4-D and

13 the herbicide glyphosate showed a slight increase of accumulation in GST transcripts

14 (Figure 4A). Incubation in presence of the herbicides metolachlor and atrazine, and the

15 insecticide dichlorvos strongly induced expression of the three GST genes. The major

16 effects were observed for CCGST1 with 23-fold induction by metolachlor and 18-fold

17 induction by dichlorvos. Heavy metals caused a modest repression effect on GST gene

18 transcription, with a maximum of a 2 -fold decrease. The most marked effects were

19 observed after incubation in the presence of fatty acid derivatives. MeJA treatment

20 induced a 6- to 43-fold change in transcript accumulation. Similar ranges of induction

21 were observed with oxylipins, stronger effects being obtained with 13(S)-HpODE on

22 CcGST2 (12-fold) for the C18 derivatives, and with 15(S)-HETE on CcGST3 (80-fold)

23 for the $\mathrm{C} 20$ derivatives. 
In the brown alga $L$. digitata, elicitors released after wounding and degradation

2 of the cell wall such as oligoguluronates are recognized as defense signals and induce an

3 oxidative burst in the alga [28]. LdGST genes were all induced by the oligoguluronates

4 (4 to 24-fold), LdGST4 being the most up-regulated gene (Figure 4B). A similar pattern

5 of variation was obtained in presence of copper, with LdGST2 being the most up-

6 regulated (30-fold). In presence of fatty acid derivatives, slight changes of transcript

7 levels were observed with 15(S)-HETE, while MeJA caused a repression with a

8 maximum of a 6-fold decrease for LdGST1.

\section{Biochemical studies of algal GST}

11 In order to investigate the biochemical features and to determine the catalytic properties

12 of the GST enzymes from both algae, the GST genes presently described were assayed

13 for heterologous expression in Escherichia coli. Only CcGST2 and LdGST3 were

14 selected for further investigation since they were the most highly expressed in the

15 soluble fraction. Migration on SDS-PAGE gels of these enzymes showed that the

16 purified proteins gave single bands of $26 \mathrm{kDa}$. Gel-filtration chromatography analysis

17 showed a single peak with molecular mass of $52 \mathrm{kDa}$ for both GSTs, strongly

18 suggesting that the active form of these enzymes exhibits homodimeric structures (see

19 Supplementary Figure S3).

20 The catalytic specificities of CcGST2 and LdGST3 were explored using a range

21 of GST substrates. In presence of the commonly used CDNB, the two algal GSTs

22 exhibited moderate transferase activity (Table 1). Higher transferase activities were

23 measured towards several model aryl halide substrates, as illustrated by the results

24 obtained with CcGST2 in presence of 1-fluoro-2,4-dinitrobenzene (FDNB; $20.34 \mu \mathrm{mol}$ 
$\left.1 \min ^{-1} \mathrm{mg}^{-1}\right)$. Slight transferase activities were also observed with one aldehyde of the

$2 \alpha, \beta$-unsaturated carbonyls, the 4-HNE. No activity was detected with the para-

3 nitrophenyl acetate substrate. The algal GSTs were also incubated in presence of the

4 synthetic cumene hydroperoxide and t-butyl hydroperoxide substrates to ascertain their

5 glutathione peroxidase activity. Results show that the recombinant enzymes exhibited

6 similar moderate activity to reduce cumene hydroperoxide (Table 1). In addition, both

7 proteins had activity towards hydroperoxides of C18 polyunsaturated fatty acids (13-

8 HpODE and 13-HpOTE).

The $\mathrm{Km}$ values of CcGST2 and LdGST3 for GSH in presence of CDNB were

10 calculated to be 0.9 and $1.1 \mathrm{mM}$ respectively (see Supplementary Table S4).

11 Measurement of GST activity through a wide range of $\mathrm{pH}$ for the two purified

12 recombinant enzymes indicated that optimal $\mathrm{pH}$ was 8 and 10 for CcGST2 and LdGST3

13 respectively (see Supplementary Figure S4).

14 To complete these data, inhibiting assays were also performed and results are

15 presented in Table 2. Cibacron blue, a typical ligandin-type inhibitor, showed the most

16 potent inhibition effect ( $\mathrm{IC}_{50}$ of 0.5 and $0.1 \mu \mathrm{M}$ for CcGST2 and LdGST3 respectively),

17 whereas chenodeoxycholic acid, lithocholic acid, indomethacin and acetyl salicylic acid

18 did not show any marked inhibition effect on the activity of either enzyme. 


\section{DISCUSSION}

2

3 The soluble glutathione transferases constitute a widespread enzyme superfamily that

4 has been subdivided into an ever-increasing number of classes [29]. While there are no

5 clearly established criteria concerning the extent of sequence similarity required for

6 placing a GST in a particular class, it is generally accepted that GSTs of the same class

7 share more than ca. 50\% sequence identity, while GSTs of different classes share less

8 than ca. $30 \%$ identity $[23,30]$. Some of these classes are ubiquitous all the way up to the

9 kingdom level, whereas others are exclusively found in particular groups of organisms

10 such as mammals, plants or insects. As large-scale EST and genomic approaches are

11 being applied to previously uninvestigated phyla, new GST genes and even new GST

12 classes are being discovered. Here we identified and characterized GST genes from two

13 independent eukaryotic lineages, the Rhodophyta (red algae) and the Heterokonta

14 (brown algae and oomycetes).

15 The phylogenetic analyses showed that the GST sequences from the red and

16 brown algae, along with some oomycetes, fall into a distinctive, newly identified group.

17 Within this new cluster, sequences may be assigned to several sub-groups: GtGST

18 sequences are closely related to CcGST sequences, while EsGST3, EsGST4 and

19 LdGST4 group together, LdGST1, LdGST2, LdGST3 and EsGST1 appear to form

20 another group. This grouping is further supported by evidence for distinct gene

21 structure. The LdGST1, LdGST2 and LdGST3 genes are intronless, while CcGST1 and

22 CCGST2 genes contain a single intron, and the LdGST4 gene has three introns. In

23 addition, it is interesting to note that the brown algal sequences appear to be more

24 closely related to the red algal enzymes than to the P. sojae sequences. Considering the 
1 common evolutionary history of oomycetes and brown algae in the heterokont lineage,

2 their respective GST members were expected to group in the same cluster. The

3 divergence among the sequences identified in this work is also illustrated by long

4 branch lengths, of great magnitude compared to the Alpha-, Mu- and Pi-class clusters

5 whose members are much more closely related to each other. This higher evolutionary

6 rate may also reflect an adaptive response to habitat. It is tempting to suggest that this

7 unexpected topology results from convergent evolution of algal enzymes in response to

8 a specific adaptation to the marine environment.

This new set of GSTs are closely related to the Sigma GST enzymes which is

10 encountered in both vertebrates and invertebrates, while the Alpha, Pi and Mu members

11 are only found in vertebrates [31]. It was initially suggested that the Alpha-class

12 enzymes were the oldest members of this clade and that they had been subsequently lost

13 in invertebrates $[9,29,31]$. In contrast, Frova [23] recently proposed that the Sigma-

14 class GSTs diverged before the Alpha, $\mathrm{Mu}$ and Pi group and has evolved distinct

15 functional properties in the diverse lineages. The occurrence of sequences closely linked

16 to the Sigma enzymes in algae and oomycetes supports this last hypothesis suggesting

17 that the entire Sigma class emerged before the eukaryotes split and diverged extensively

18 later in independent lineages.

19 Among the GST genes isolated from the red algae, CcGST3 represents an 20 intriguing sequence. It exhibits only low similarity with other GSTs from an algal 21 origin. No intron was found in its gene sequence. Despite the fact that we cannot rule 22 out a bacterial origin for this GST, several observations point towards CcGST3 being an 23 endogenous algal sequence: a polyA tail is present at the end of the corresponding 24 mRNA and the likely active sites residues of the encoded protein may be different from 
1 the ones encountered in prokaryotic GSTs. Indeed, GSH-binding is known to involve a

2 conserved cystein residue in the N-terminal portion of the bacterial GSTs. While no

3 such residue is found in the putative GSH-binding domain of CcGST3 (see

4 Supplementary Figure S1), two tyrosine residues are encountered in its N-terminal

5 portion which may play this role. In addition, and as discussed below, CCGST3 follow a

6 transcription pattern similar to the others CCGSTs and sometimes being the most

7 affected during the treatments.

8 Biotic stress and chemicals are known to affect the expression of GSTs at the

9 transcriptional level [1], transcript accumulations for C. crispus and L. digitata genes

10 were determined in response to various treatments. The seven identified genes were

11 constitutively expressed in the two algae. The basal levels of expression were lower for

12 the LdGST genes than for the CcGST genes. CcGST2 was expressed at the same level as

13 the housekeeping gene actin, indicating that this GST protein plays a major role in the

14 basic metabolism of C. crispus. CCGST genes were highly induced by the herbicides

15 atrazine and metolachlor and the insecticide dichlorvos. This increase in gene

16 expression was correlated with a higher GST activity in total extracts of the red alga

17 treated during 24 hours with metolachlor and dichlorvos (data not shown). The red

18 macroalgae may therefore have the potential to remove xenobiotic pollutants from their

19 environment.

20 In contrast to these results and considering what is known in higher plants [32]

21 heavy metals such as cadmium, copper, zinc and aluminium caused a decrease in

22 expression of the three CCGST genes. Opposite results were observed for the LdGST

23 genes during treatment with $\mathrm{CuSO}_{4}$. Incubation of L. digitata sporophytes with

24 oligoguluronates resulted in a strong induction of its GST genes. These oligosaccharides 
1 are recognized as endogenous elicitors by the alga, inducing oxidative burst production

2 as part of the active defense system [28]. Copper has also been shown to activate

3 transient massive release of reactive oxygen species in this alga (data not shown).

4 Therefore the accumulation of LdGST transcripts may be mediated through induced

$5 \quad \mathrm{H}_{2} \mathrm{O}_{2}$ production. This hypothesis is not relevant for $C$. crispus since application of an

6 oxidative stress seems to have almost no effect on the accumulation of CcGST

7 transcripts.

Interestingly, contrasting results were also obtained for GST from both algae in

9 presence of oxylipins derived from C18 and C20 polyunsaturated fatty acids. Several

10 oxylipin structures have been described so far in marine algae, some of them being

11 closely related, and even identical, to those identified in terrestrial plants (C18-

12 derivatives; [33]) and mammals (C20-derivatives; [34]). Their biological functions

13 remain elusive, despite the fact that some of them have been demonstrated to act as

14 potential defense and signaling mediators in red marine alga [35]. The present study

15 demonstrated that $\mathrm{C} 18$ and $\mathrm{C} 20$ oxylipins greatly increased levels of CcGST transcripts,

16 confirming previous results obtained after treatment of C. crispus with MeJA. The

17 precise roles of CcGST during these treatments are unknown. They may be expressed as

18 active participants in a more global defense response to detoxify by-products released

19 during biotic stresses. However, they could also have a more dedicated function, such as

20 a potential involvement in fatty acid and oxylipin metabolism. Since the tested oxylipins

21 had the opposite effect on LdGST genes, these molecules may have different roles in the

22 two algae, and/or GSTs may not drive similar processes in the two lineages.

23 It is also worth noting that, despite structural differences in gene organization

24 among GST genes within a species, all GSTs from the same alga exhibited a similar 
1 transcription profile. This probably suggests functional convergence of these enzymes

2 within a species, and their importance in specific metabolic pathways. Further

3 experiments are required to identify the biological significance of this result.

4 Expression and purification of recombinant CcGST and LdGST enzymes in E. coli

5 made it possible to characterize the properties of these proteins. The catalytic profile of

6 CcGST2 was similar to that of LdGST3, but the red alga GST showed greater activity

7 towards FDNB substrates. In contrast, LdGST3 exhibited a higher transferase activity in

8 presence of 4-HNE, an electrophilic end-product of lipid peroxidation. Both enzymes

9 have no activity on the related compound trans-2-nonenal. In addition to their

10 glutathione transferase activity, both enzymes are able to reduce organic hydroperoxides

11 of fatty acids. This peroxidase activity might play a role in the algae during oxidative

12 stress, in preventing the production of cytotoxic aldehydes from the organic

13 hydroperoxides. Algal GST Km values illustrate a moderate affinity substrate to GSH.

14 These results are however in agreement with published $\mathrm{Km}^{\mathrm{GSH}}$ values for other GST

15 (Konishi et al., 2005, Park et al., 2005, Urade et al., 1987, Zeng et al., 2005).

16 In addition to detoxifying electrophilic compounds, there is growing evidence

17 that GST members carry out additional functions. The GST activities are quite diverse,

18 not only between, but also within classes, as demonstrated for members of the Sigma

19 class. For example, in cephalopods, S-crystallin proteins are highly abundant in eye

20 lenses, and have lost their GST activity due to insertion of 11 residues between the

21 conserved $\alpha 4$ and $\alpha 5$ helixes [36]. In Drosophila melanogaster, Sigma-type GSTs have

22 considerable activities towards $\alpha, \beta$-unsaturated carbonyl compounds derived from a

23 secondary lipid-peroxidation [37]. In vertebrates, they are known as glutathione-

24 dependent prostaglandin D-synthases (PGDS), catalysing the isomerisation of 
1 prostaglandin $\mathrm{H} 2$ to prostaglandin D2 [21]. This activity is also conserved in the Sigma

2 GST from the parasitic flatworms Schistosoma [38], despite their distinct phylogenetic 3 position.

We previously described the production of cyclopentenonic prostaglandins of

5 the A2, B1, B2 and E2 series after various treatments in C. crispus [35]. In mammals,

6 these molecules are produced by cyclooxygenases [39], and pharmacological studies

7 have shown that acetyl salicylic acid and indomethacin inhibits specifically these

8 enzymes [40]. In the red alga, the enzymatic machinery involved in the production of

9 prostaglandins remains elusive. However, synthesis of these cyclopentenones in $C$.

10 crispus is strongly affected in presence of cibacronblue, while no alteration was

11 monitored in presence of either indomethacin or acetyl salicylic acid (data not shown).

12 Interestingly, similar inhibitor action has been observed on CcGST2 activity. Therefore,

13 we are currently undertaking further experiments to determine if this GST might play a

14 role in prostaglandin synthesis in C. crispus.

15 To conclude, the increasing number of genomic projects dealing with previously

16 uninvestigated lineages will probably greatly modify our current knowledge on the

17 evolution diversity and function of GSTs in the near future. As illustrated in the present

18 study with GSTs characterized from C. crispus and L. digitata, the challenge lies in

19 identifying their functions, not necessarily associated with detoxification. Further

20 investigations on these proteins, including structural biology approaches, may provide

21 some clues on the catalytic specificities and physiological functions of these enzymes in macroalgae. 
2 C. Hervé was supported by a BDI fellowship from the Centre National de la Recherche

3 Scientifique. PO de Franco was supported by the French Ministère de 1'Enseignement

4 Supérieur et de la Recherche. We thank G. Michel for technical support and helpful

5 advice on structural alignment analyses. We are grateful to F. Morel for supplying GST

6 substrates as well as for valuable discussion and to M. Cock for providing access to the

7 E. siliculosus EST database. Part of this work was performed in the framework of the

8 "Marine Genomics Europe" NoE (EC contract N GOCE-CT-2004-505403).

11 SUPPLEMENTARY DATA

13 The following supplementary data is available for this article:

14 Figure S1 Alignment of the predicted amino acid sequence of CcGST3 with 15 sequences from the Beta and Delta classes

16 Figure S2 Maximum likelihood phylogenetic tree showing the relationship between

17 selected GSTs from algae and oomycetes and the Alpha, Pi, Mu and Sigma GST 18 classes

19 Figure S3 Purification of recombinant CcGST2 and LdGST3 enzymes

20 Figure S4 Effect of pH on CcGST2 and LdGST3 glutathione transferase activity

21 Table S1 List of oligonucleotide primers used in this study

22 Table S2 Concentrations of substrates used for the determination of specific

23 transferase and peroxidase activities

24 
B Biochemical Journal Immediate Publication. Published on 04 Mar 2008 as manuscript BJ20071464

1 Table S3 List of sequences used for the phylogenetic analysis

2 Table S4 Kinetic constant values for the recombinant CcGST2 and LdGST3 3

4 


\section{REFERENCES}

2

31 Dixon, D. P., Lapthorn, A. and Edwards, R. (2002) Plant glutathione transferases. Genome Biol 3, REVIEWS3004

52 Roxas, V. P., Lodhi, S. A., Garrett, D. K., Mahan, J. R. and Allen, R. D. (2000)

6 Stress Tolerance in Transgenic Tobacco Seedlings that Overexpress Glutathione

7 S-Transferase/Glutathione Peroxidase. Plant. Cell. Physiol. 41, 1229-1234

83 Thom, R., Dixon, D. P., Edwards, R., Cole, D. J. and Lapthorn, A. J. (2001) The structure of a zeta class glutathione S-transferase from Arabidopsis thaliana: characterisation of a GST with novel active-site architecture and a putative role in tyrosine catabolism. J. Mol. Biol. 308, 949-962

124 Mueller, L. A., Goodman, C. D., Silady, R. A. and Walbot, V. (2000) AN9, a Petunia Glutathione S-Transferase Required for Anthocyanin Sequestration, Is a Flavonoid-Binding Protein. Plant. Physiol. 123, 1561-1570

155 Gong, H., Jiao, Y., Hu, W. W. and Pua, E. C. (2005) Expression of glutathione-

16 S-transferase and its role in plant growth and development in vivo and shoot

17 morphogenesis in vitro. Plant. Mol. Biol. 57, 53-66

186 Pearson, W. R. (2005) Phylogenies of Glutathione Transferase Families.

19 Methods in Enzymology 401, 186-204

207 Ranson, H., Rossiter, L., Ortelli, F., Jensen, B., Wang, X., Roth, C. W., Collins, 21 F. H. and Hemingway, J. (2001) Identification of a novel class of insect 22 glutathione S-transferases involved in resistance to DDT in the malaria vector 23 Anopheles gambiae. Biochem. J 359, 295-304 
18 Rossjohn, J., Polekhina, G., Feil, S. C., Allocati, N., Masulli, M., Ilio, C. D. and

2 Parker, M. W. (1998) A mixed disulfide bond in bacterial glutathione

3 transferase: functional and evolutionary implications. Structure 6, 721-734

49 Armstrong, R. N. (1997) Structure, catalytic mechanism, and evolution of the

5 glutathione transferases. Chem. Res. Toxicol. 10, 2-18

610 Baldauf, S. L., Roger, A. J., Wenk-Siefert, I. and Doolittle, W. F. (2000) A

7 kingdom-level phylogeny of eukaryotes based on combined protein data.

$8 \quad$ Science 290, 972-977

911 Collén, J., Roeder, V., Rousvoal, S., Collin, O,, Kloareg, B. and Boyen, C.

10 (2006a) An expressed sequence tag analysis of thallus and regenerating

11 protoplasts of Chondrus crispus (Gigartinales, Rhodophyceae). J. Phycol. 42,

$12 \quad 104-112$

1312 Roeder, V., Collén, J., Rousvoal, S., Corre, E., Leblanc, C. and Boyen, C. (2005)

14 Identification of stress genes transcripts in Laminaria digitata (Phaeophyceae)

15 protoplast cultures by expressed sequence tag analysis. J. Phycol. 41, 1227-1235

1613 Correa, J. A., Nielsen, R. and Grund, D. W. (1988) Endophytic algae of

17 Chondrus crispus (Rhodophyta). II. Acrochaete heteroclada sp. nov., A.

18 operculata sp. nov., and Phaeophyla dendroides (Chlorophyta). J. Phycol. 24,

$19 \quad 528-539$

2014 Boyen, C, Kloareg, B., Polne-Fuller, M. and Gibor, A. (1990) Preparation of 21 alginate lyases from marine molluscs for protoplast isolation in brown algae.

22 Phycologia 29, 173-181 
115 Hervé, C., Tonon, T., Collén, J., Corre, E. and Boyen, C. (2006) NADPH

2 oxidases in Eukaryotes: red algae provide new hints! Current Genetics V49,

$3 \quad 190-204$

416 Collén, J., Herve, C., Guisle-Marsollier, I., Leger, J. J. and Boyen, C. (2006b)

5 Expression profiling of Chondrus crispus (Rhodophyta) after exposure to methyl

$6 \quad$ jasmonate. J. Exp. Bot. 57, 3869-3881

717 Edgar, R. C. (2004) MUSCLE: multiple sequence alignment with high accuracy

$8 \quad$ and high throughput. Nucl. Acids Res. 32, 1792-1797

918 Kumar, S., Tamura, K. and Nei, M. (2004) MEGA3: Integrated software for

10 Molecular Evolutionary Genetics Analysis and sequence alignment. Brief

11 Bioinform 5, 150-163

1219 Guindon, S., Lethiec, F., Duroux, P. and Gascuel, O. (2005) PHYML Online--a

13 web server for fast maximum likelihood-based phylogenetic inference. Nucl.

$14 \quad$ Acids Res. 33, W557-559

1520 Studier, F. W. (2005) Protein production by auto-induction in high density

16 shaking cultures. Protein. Expr. Purif. 41, 207-234

1721 Thomson, A. M., Meyer, D. J. and Hayes, J. D. (1998) Sequence, catalytic

18 properties and expression of chicken glutathione-dependent prostaglandin D2

19 synthase, a novel class Sigma glutathione S-transferase. Biochem. J. 333 ( Pt 2),

$20 \quad 317-325$

2122 Alin, P., Danielson, U. H. and Mannervik, B. (1985) 4-Hydroxyalk-2-enals are

22 substrates for glutathione transferase. FEBS Letters 179, 267-270

2323 Frova, C. (2006) Glutathione transferases in the genomics era: New insights and 24 perspectives. Biomolecular Engineering 23, 149-169 
124 Konishi, T., Kato, K., Araki, T., Shiraki, K., Takagi, M. and Tamaru, Y. (2005)

2 A new class of glutathione S-transferase from the hepatopancreas of the red sea

3 bream Pagrus major. Biochem. J. 388, 299-307

425 Bryant, D., Cummins, I., Dixon, D. P. and Edwards, R. (2006) Cloning and

5 characterization of a theta class glutathione transferase from the potato pathogen

$6 \quad$ Phytophthora infestans. Phytochemistry 67, 1427-1434

726 Marco, A., Cuesta, A., Pedrola, L., Palau, F. and Marin, I. (2004) Evolutionary

8 and Structural Analyses of GDAP1, Involved in Charcot-Marie-Tooth Disease,

9 Characterize a Novel Class of Glutathione Transferase-Related Genes. Mol.

$10 \quad$ Biol. Evol. 21, 176-187

1127 Snyder, M. J. and Maddison, D. R. (1997) Molecular phylogeny of glutathione-

12 S-transferases. DNA Cell. Biol. 16, 1373-1384

1328 Kupper, F. C., Kloareg, B., Guern, J. and Potin, P. (2001) Oligoguluronates

14 elicit an oxidative burst in the brown algal kelp Laminaria digitata. Plant

$15 \quad$ Physiol 125, 278-291

1629 Sheehan, D., Meade, G., Foley, V. M. and Dowd, C. A. (2001) Structure,

17 function and evolution of glutathione transferases: implications for classification

18 of non-mammalian members of an ancient enzyme superfamily. Biochem. J.

$19360,1-16$

2030 Hayes, J. D., Flanagan, J. U. and Jowsey, I. R. (2005) Glutathione transferases.

21 Annu. Rev. Pharmacol. Toxicol. 45, 51-88

2231 Pearson, W. R. (2005) Phylogenies of Glutathione Transferase Families,

23 Academic Press 
132 Elbekai, R. H. and El-Kadi, A. O. (2004) Modulation of aryl hydrocarbon receptor-regulated gene expression by arsenite, cadmium, and chromium. Toxicology 202, 249-269

433 Krupina, M. and Dathe, W. (1991) Occurence of jasmonic acid in the red alga

\section{Gelidium latifolium. Z. Naturfosch [C] 46, 1127-1129}

Sajiki, J. and Kakimi, H. (1998) Identification of eicosanoids in the red algae, Gracilaria asiatica, using high-performance liquid chromatography and electrospray ionization mass spectrometry. J. Chromatogr. A 795, 227-237

35 Bouarab, K., Adas, F., Gaquerel, E., Kloareg, B., Salaun, J. P. and Potin, P. (2004) The innate immunity of a marine red alga involves oxylipins from both the eicosanoid and octadecanoid pathways. Plant. Physiol. 135, 1838-1848 Chang, H. C., Lin, T. L. and Chang, G. G. (2000) Molecular basis for the polymerization of octopus lens S-crystallin. Biophys. J. 78, 2070-2080

37 Agianian, B., Tucker, P. A., Schouten, A., Leonard, K., Bullard, B. and Gros, P. (2003) Structure of a Drosophila sigma class glutathione S-transferase reveals a novel active site topography suited for lipid peroxidation products. J. Mol. Biol. 326, $151-165$

Johnson, K. A., Angelucci, F., Bellelli, A., Herve, M., Fontaine, J., Tsernoglou, D., Capron, A., Trottein, F. and Brunori, M. (2003) Crystal structure of the 28 kDa glutathione S-transferase from Schistosoma haematobium. Biochemistry 42 , 10084-10094

Funk, C. D. (2001) Prostaglandins and leukotrienes: advances in eicosanoid biology. Science 294, 1871-1875 
B Biochemical Journal Immediate Publication. Published on 04 Mar 2008 as manuscript BJ20071464

140 Simmons, D. L., Botting, R. M. and Hla, T. (2004) Cyclooxygenase Isozymes:

2 The Biology of Prostaglandin Synthesis and Inhibition. Pharmacol. Rev. 56,

3 $387-437$

4 
1 Table 1 Substrate specificities of the recombinant CcGST2 and LdGST3

2

\begin{tabular}{lrr}
\hline \multirow{2}{*}{ Substrate } & \multicolumn{2}{c}{$\begin{array}{c}\text { Specific activity } \\
\left(\mu \mathrm{mol} . \mathrm{min}^{-1} \cdot \mathrm{mg}^{-1} \text { of protein) }\right.\end{array}$} \\
\cline { 2 - 3 } & \multicolumn{1}{c}{ CcGST2 } & \multicolumn{1}{c}{ LdGST3 } \\
\hline Aryl halides & & $0.98 \pm 0.10$ \\
1-chloro-2,4-dinitrobenzene (CDNB) & $1.56 \pm 0.08$ & $3.34 \pm 0.04$ \\
1-bromo-2,4-dinitrobenzene (BDNB) & $1.56 \pm 0.08$ & $7.44 \pm 0.66$ \\
1-fluoro-2,4-dinitrobenzene (FDNB) & $20.34 \pm 0.59$ & $1.29 \pm 0.11$ \\
1-iodo-2,4-dinitrobenzene (IDNB) & $3.84 \pm 0.12$ & not detected \\
para-nitrobenzoyl chloride & not detected & \\
& & not detected \\
$\alpha, \beta$-unsaturated carbonyls & & not detected \\
Ethacrynic acid & not detected & $0.69 \pm 0.01$ \\
trans-4-phenyl-3-buten-2-one & not detected & not detected \\
4-hydroxynonenal (4-HNE) & $0.20 \pm 0.02$ & \\
trans-2-nonenal & not detected & not detected \\
Miscellaneous & & \\
para-nitrophenyl acetate & not detected & \\
Organic hydroperoxides & & $0.12 \pm 0.01$ \\
Cumene hydroperoxide & & $0.61 \pm 0.12$ \\
$t$-butyl hydroperoxide & $0.15 \pm 0.03$ & $0.06 \pm 0.01$ \\
13-HpODE & $0.04 \pm 0.01$ & $0.08 \pm 0.01$ \\
13-HpOTE & $0.23 \pm 0.01$ & \\
\hline
\end{tabular}

4

5 Results are expressed as means \pm SD of four determinations.

6 
1 Table 2 Inhibitor sensitivities of recombinant CcGST2 and LdGST3

\begin{tabular}{lccc}
\hline \multirow{2}{*}{ Compound } & $\begin{array}{c}\text { Inhibitor concentration } \\
\text { range }(\mu \mathrm{M})\end{array}$ & \multicolumn{2}{c}{$\mathrm{IC}_{50}(\mu \mathrm{M})$} \\
\cline { 3 - 4 } & $0-10$ & $\mathrm{CcGST}^{2}$ & LdGST3 \\
\hline Cibacron Blue & $0-1000$ & 564 & 0.1 \\
Chenodeoxycholic acid & $0-1000$ & 119 & 93 \\
Lithocholic acid & $0-1000$ & 623 & 83 \\
Indomethacin & $0-1000$ & $>1000$ & $>1000$ \\
Acetyl salicylic acid & & & 71 \\
\hline
\end{tabular}

2

3 Results are expressed as the mean of four determinations. 


\section{FIGURE LEGENDS}

2

3 Figure 1 Alignment of GST amino-acid sequences from C. crispus and L. digitata

\section{4 with mammalian sequences from the Sigma class}

5 Conserved amino acids highlighted in black are identical and residues boxed in grey are

6 similar. Known secondary structure of the human sequence HsGSTS1 is shown above

7 the alignment. Alpha helixes and beta strands are represented as helixes and arrows

8 respectively, and beta turns are marked with TT. Potential catalytically important

9 residues involved in GSH-binding are shown as filled arrowheads. This alignment was

10 created using the following sequences (organism, Genbank/PDB accession numbers):

11 HsGSTS1 (Homo sapiens, AAH20734, 1IYI), RnGSTS1 (Rattus norvegicus,

12 NP8113832).

14 Figure 2 Exon/intron structure of genes encoding GSTs in C. crispus and L. digitata

15 The genomic DNA sequences of coding regions are represented; solid rectangles denote 16 exons. A scale bar is given.

18 Figure 3 Unrooted neighbor-joining phylogenetic tree showing the relationship

19 between GSTs from algae, oomycetes and the major GST classes.

20 Clustering of proteins into GST classes is indicated. Numbers in brackets refer to the

21 number of sequences included for each class that have been collapsed in the figure. The numbers on the branches indicate the percentage of node support from 1,000 bootstrap replicates. 
1 Figure 4 Real-time PCR analysis of $C$. crispus and L. digitata GST genes after

\section{2 different chemical treatments}

3 The relative gene expression ratios for the GST transcripts were calculated as described

4 in the Experimental procedures. (a) Expression profile of GST transcripts from the red

5 alga C. crispus. A set of 16 products was tested, including six pesticides, four heavy

6 metals and five fatty acid derivatives. (b) Expression profile of GST transcripts from the

7 brown alga L. digitata. Oligoguluronates, known as endogenous oligosaccharide

8 elicitors, were tested, as one heavy metal and two fatty acid derivatives.

9 Bars: standard errors. Values represent the mean of two determinations from three 10 independent biological samples.

11 
HSPGDS1

HsPGDS1 RnPGDS1 CCGST1 CCGST2 LdGST1 LdGST2 LaGST2 LdGST3

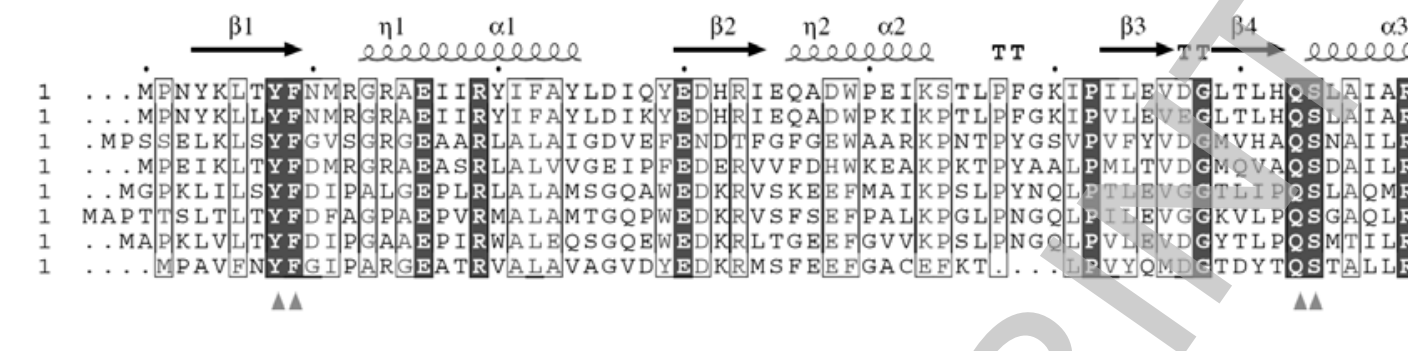

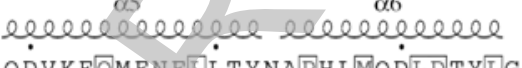

HSPGDS1 HsPGDS1 RnPGDS1 CCGST1 CCGST2 LdGST1 LdGST2 LdGST 3 LdGST4

elebelelebelee

$\mathrm{T} \mathrm{T}$

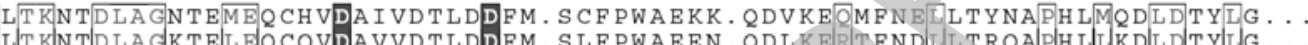

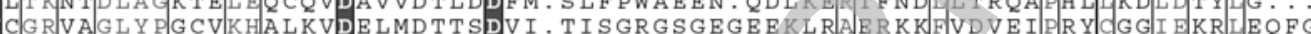
C T

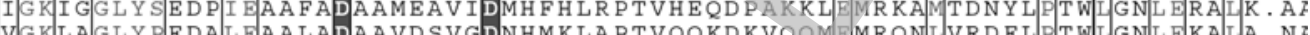

VGKIG

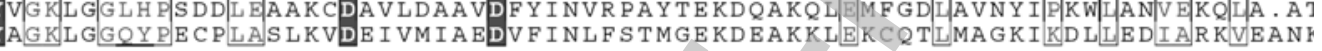

HSPGDS1

т T lecelelelelele

$\alpha 8$

$\alpha 9$

HsPGDS1

RnPGDS 1

CCGST1

CCGST2

LdGST1

LdGST2
LdGST3

LdGST4

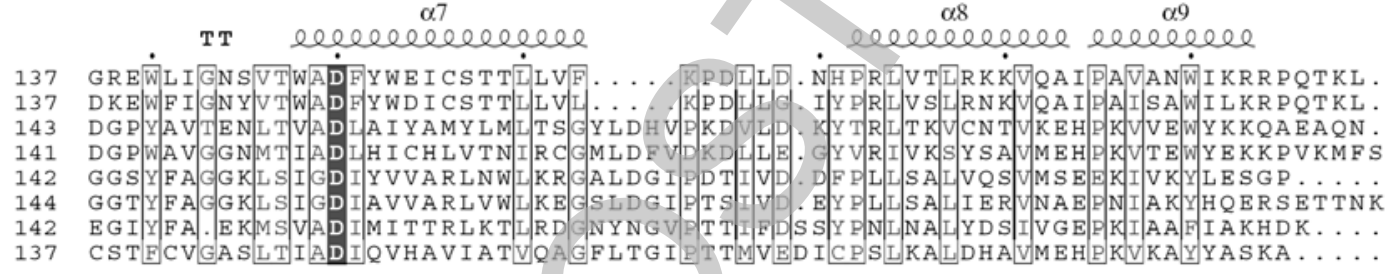

2

3

4

\section{$5 \quad$ Figure 1}
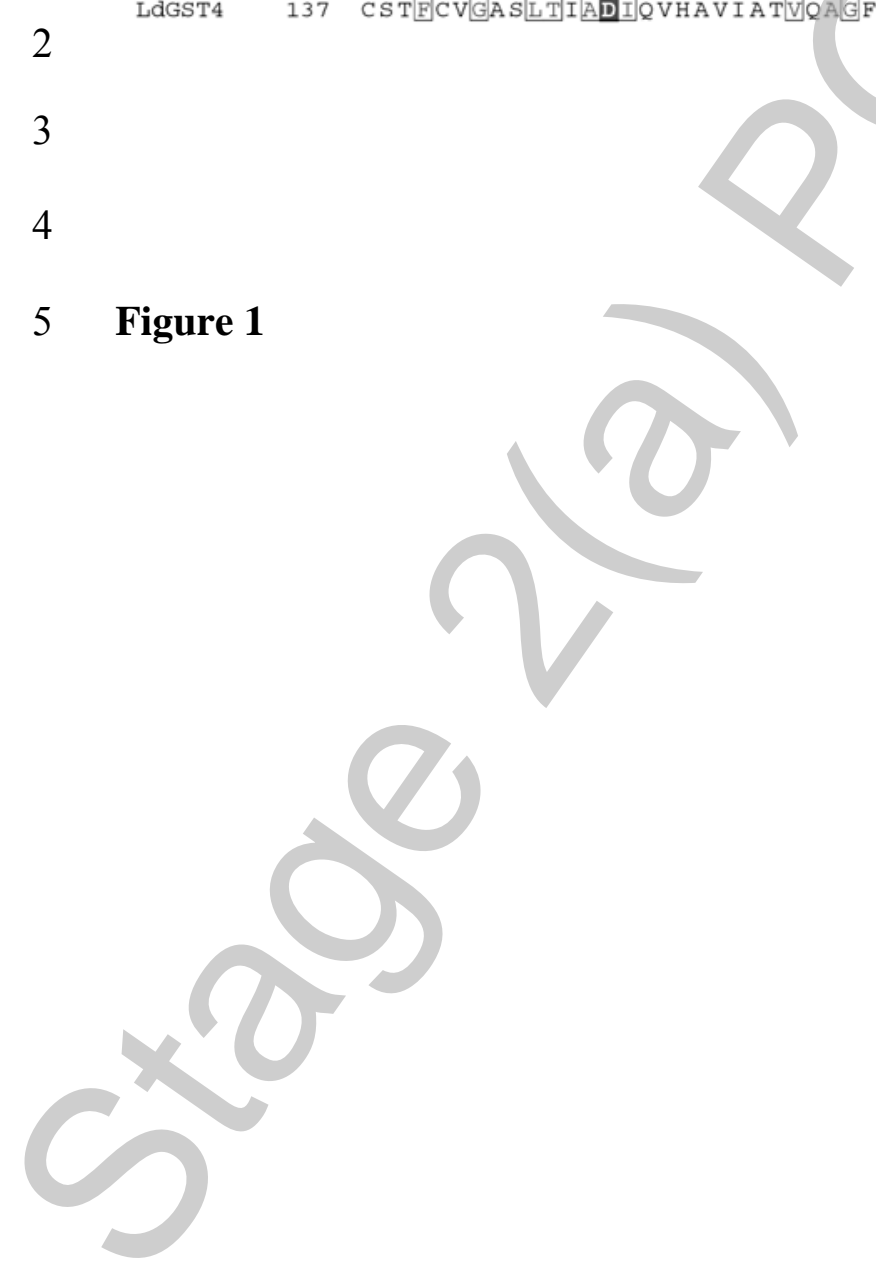
Chondrus crispus

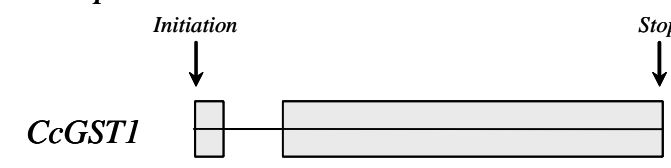

CCGST2 $\square \square$

\begin{tabular}{lll}
\hline Gene & Gene character & Size $(\mathrm{bp})$ \\
\hline \multirow{2}{*}{ CcGST1 } & Exon 1 & 43 \\
& Intron 1 & 93 \\
& Exon 2 & 587 \\
\multirow{4}{*}{ CCGST2 } & Exon 1 & 37 \\
& Intron 1 & 100 \\
& Exon 2 & 590 \\
\hline
\end{tabular}

$100 \mathrm{bp}$

CcGST3

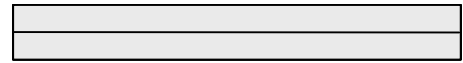

$\stackrel{100 \mathrm{p}}{\longrightarrow}$

Laminaria digitata
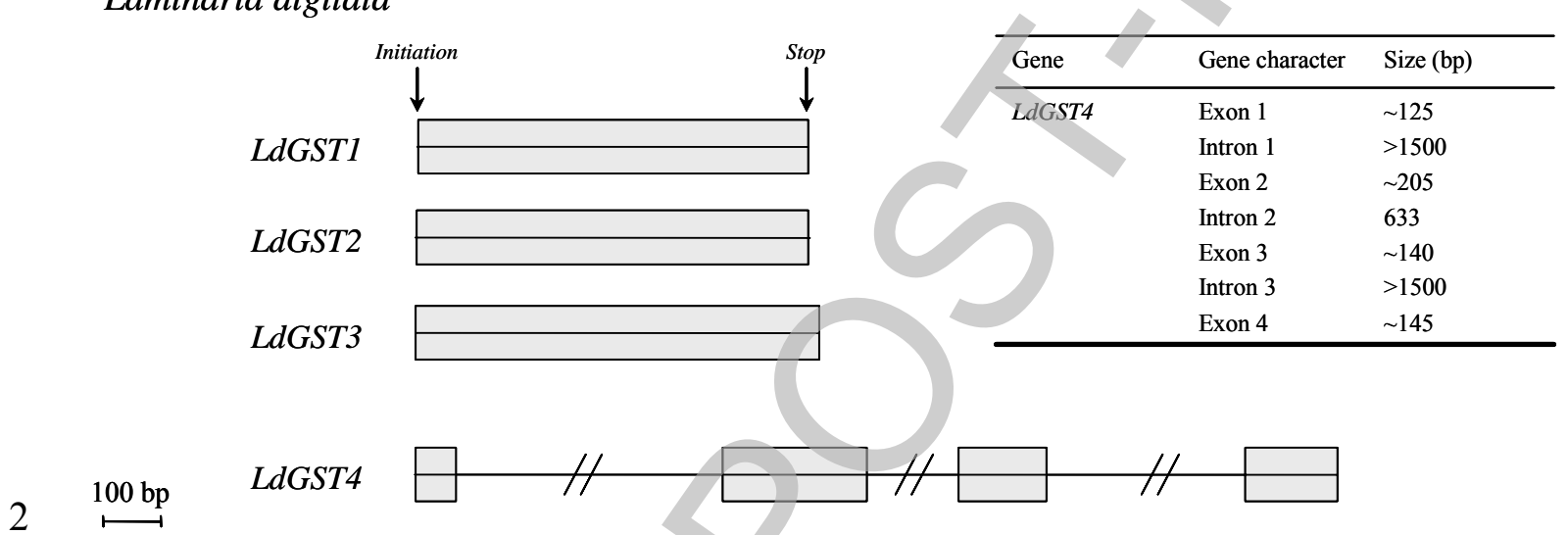

3

$4 \quad$ Figure 2

5

Licenced copy. Copying is not permitted, except with prior permission and as allowed by law. (C) 2008 The Authors Journal compilation (C) 2008 Biochemical Society 


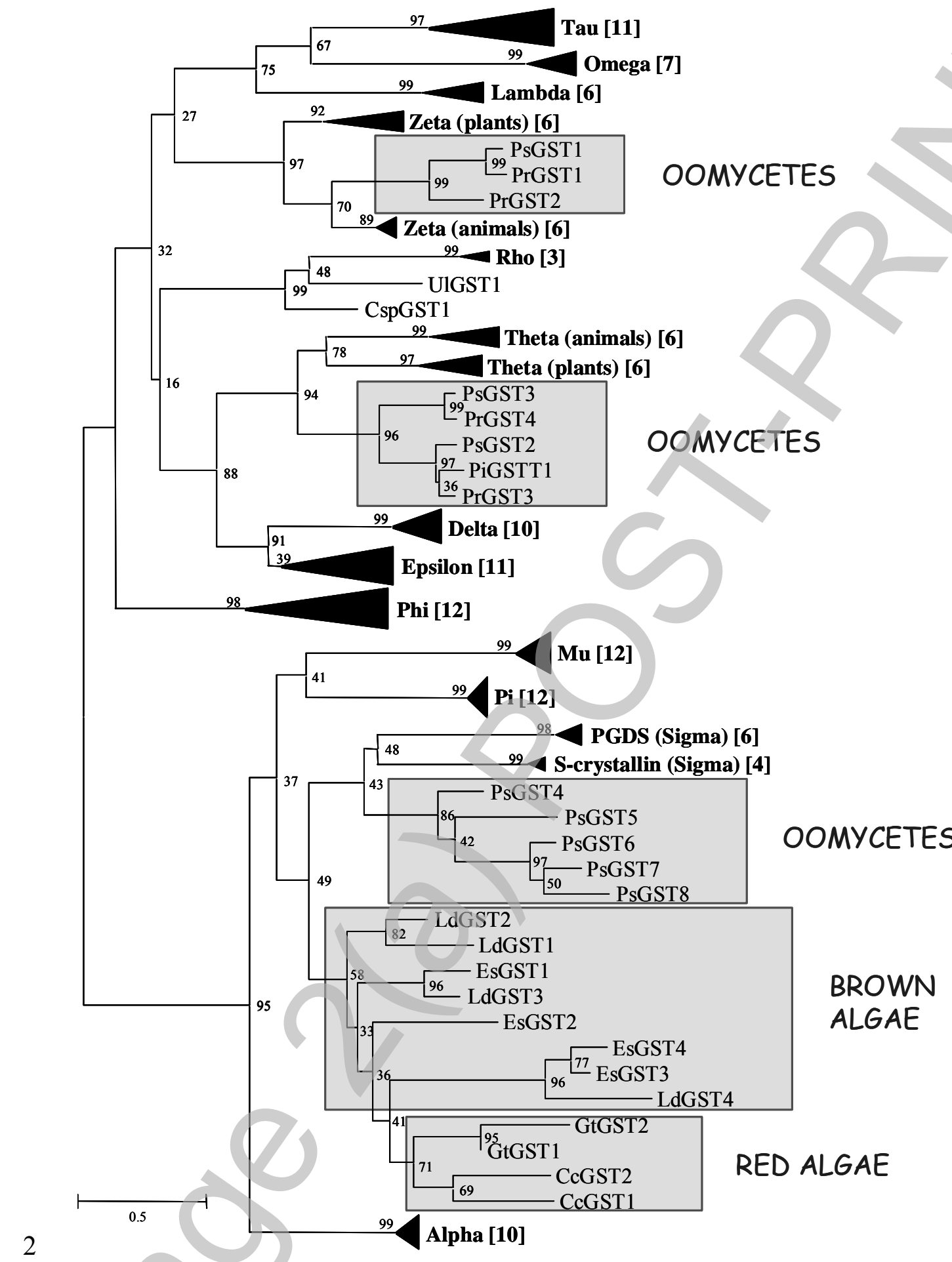

$3 \quad$ Figure 3

Licenced copy. Copying is not permitted, except with prior permission and as allowed by law. (C) 2008 The Authors Journal compilation (C) 2008 Biochemical Society 
(a)

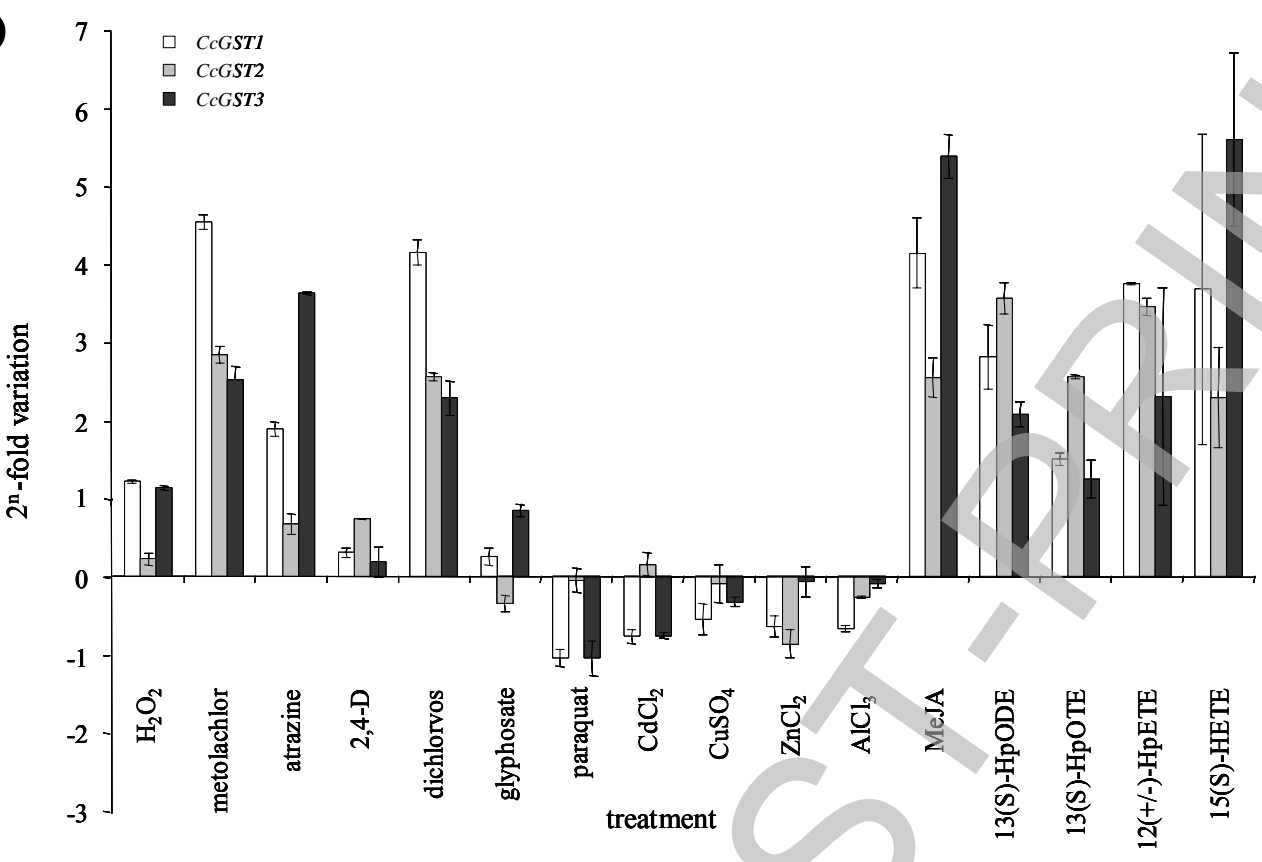

(b)

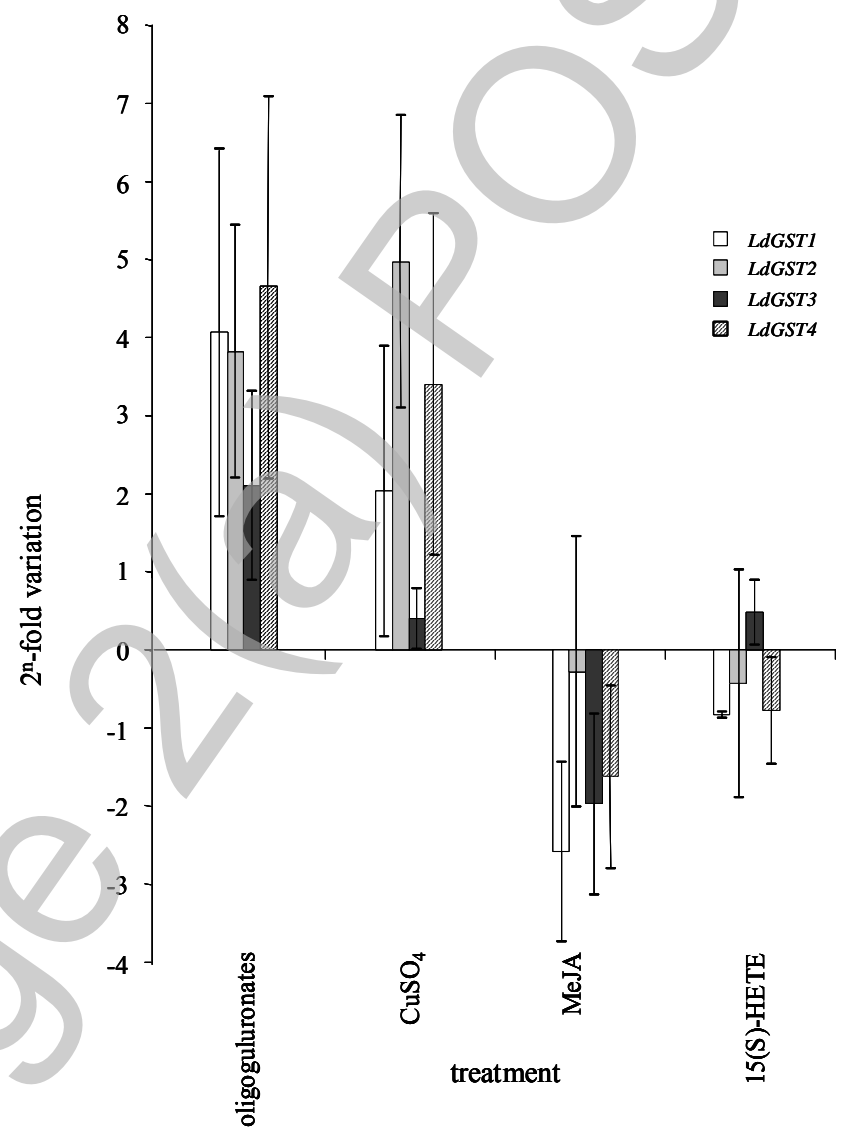

$4 \quad$ Figure 4 